Article

\title{
Synthesis of Amphiphilic Block Copolymers Containing Chiral Polythiophene Chains and Their Micelle Formation and Chiroptical Properties
}

\author{
Daisuke Hirose ${ }^{1}$, Satoru Nozaki ${ }^{1}$, Shigeyoshi Kanoh ${ }^{1}$ and Katsuhiro Maeda ${ }^{1,2, *}$ \\ 1 Graduate School of Natural Science and Technology, Kanazawa University, Kakuma-machi, \\ Kanazawa 920-1192, Japan; dhirose@se.kanazawa-u.ac.jp (D.H.); satoru3959@yahoo.co.jp (S.N.); \\ kanoh@se.kanazawa-u.ac.jp (S.K.) \\ 2 Nano Life Science Institute (WPI-NanoLSI), Kanazawa University, Kakuma-machi, \\ Kanazawa 920-1192, Japan \\ * Correspondence: maeda@se.kanazawa-u.ac.jp; Tel.: +81-76-234-4783
}

Received: 13 June 2018; Accepted: 27 June 2018; Published: 30 June 2018

\begin{abstract}
Amphiphilic block copolymers consisting of hydrophobic regioregular head-to-tail (HT) chiral ((S)-poly-1a-b-poly-3) or achiral (poly-1b-b-poly-3) polythiophene chains and a hydrophilic poly(acrylic acid) chain were synthesized. (S)-Poly-1a- $b$-poly-3 with a chiral polythiophene block formed a micelle in water that exhibited a characteristic induced circular dichroism (ICD) in the $\pi-\pi^{*}$ transition region due to the formation of supramolecular $\pi$-stacked chiral aggregates of the chiral polythiophene blocks in the core. These aggregates were stable, showing no precipitation for more than 5 days. Micelles consisting of chiral (S)-poly-1a- $b$-poly-3 and achiral poly-1b-b-poly-3 showed negative nonlinear effects on supramolecular chiral aggregate formation in the core. Chiral polythiophene aggregates formed in (S)-poly-1a-b-poly-3 micelle cores were stabilized by the crosslinking of poly(acrylic acid) blocks with diamines in the shell. The ICD intensity of the (S)-poly-1a-b-poly-3 micelle after shell crosslinking showed almost no change with temperature, while that before shell crosslinking decreased with increasing temperature.
\end{abstract}

Keywords: polythiophene; chiral aggregate; circular dichroism; micelle; crosslinking

\section{Introduction}

Regioregular (head-to-tail, HT) polythiophenes (PTs) bearing an optically active substituent are known to form supramolecular chiral aggregates in poor solvents or films. These molecules show an induced circular dichroism (CD) in the $\pi-\pi^{*}$ transition region that is attributed to the PT main chain, but show no induced CD in the same region in a good solvent [1-7]. These chiral supramolecular aggregates have attracted considerable interest owing to their promising applications, for example, in enantioselective catalysts, adsorbents, sensors, and electrodes [1-3]. However, the stability of chiral aggregates produced by intermolecular $\pi$-stacking interactions is highly dependent on external conditions, such as the solvent, temperature, and concentration. These well-organized structures cannot be maintained for long periods due to precipitation caused by excessive aggregation.

In contrast, amphiphilic block copolymers consisting of a hydrophobic chain and hydrophilic chain are known to form polymer micelles or vesicles in water. These polymer micelles are predicted to have applications as nanoreactors and drug delivery systems through the use of the hydrophobic cores as a closed molecular space [8]. Furthermore, dynamic polymer micelles can be easily transformed into stable robust nanoparticles by crosslinking the shell using a well-established procedure [9-11].

In this study, we synthesized amphiphilic block copolymers consisting of a hydrophobic chiral or achiral PT chain and a hydrophilic poly(acrylic acid) chain ((S)-poly-1a-b-poly-3 or poly-1b-b-poly-3, 
respectively) (Scheme 1). The chiroptical properties of their micelles formed in an aqueous solution were investigated using circular dichroism (CD) and absorption spectroscopy to determine whether the PT chains formed chiral supramolecular aggregates effectively in the micelle core. We also investigated the effect of shell crosslinking on the stability of the chiral aggregates formed in the micelle core.

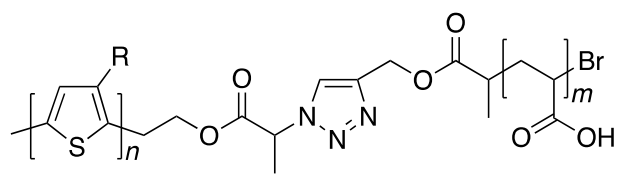

(S)-poly-1a- $b$-poly-3: $\mathrm{R}=\mathrm{R}^{1}, n=49, m=72$ poly-1b-b-poly-3: $\mathrm{R}=\mathrm{R}^{2}, n=47, m=72$

Scheme 1. Structures of (S)-poly-1a- $b$-poly-3 and poly-1b-b-poly-3.

\section{Materials and Methods}

\subsection{Reagents and Materials}

Anhydrous toluene, dichloromethane, and diethyl ether were obtained from Kanto Kagaku (Tokyo, Japan). Triethylamine (TEA) was dried over $\mathrm{KOH}$ pellets and distilled from $\mathrm{KOH}$ under nitrogen. These solvents were stored under nitrogen. Anhydrous tetrahydrofuran (THF), 3-bromothiophene, tert-butyl acrylate, trifluoroacetic acid, [1,3-bis(diphenylphosphino)propane] dichloronickel(II) (Ni(dppp)Cl $\left.l_{2}\right), N, N, N^{\prime}, N^{\prime \prime}, N^{\prime \prime}$-pentamethyldiethylenetriamine (PMDETA), and palladium on activated carbon $(\mathrm{Pd} / \mathrm{C}, 10 \mathrm{wt} \%)$ were purchased from Wako Pure Chemical Industries (Osaka, Japan). (S)-(+)-Citronellyl bromide, 2-bromopropionyl bromide, 1-[3-(dimethylamino) propyl]-3-ethylcarbodiimide methiodide, $n$-butylmagnesium chloride (2.0 M in THF), vinylmagnesium bromide (1.0 M in THF), 9-borabicyclo[3,3,1]nonane (9-BBN) (0.5 M in THF), and tetrabutylammonium fluoride (TBAF) (1.0 M in THF) were obtained from Sigma-Aldrich (Milwaukee, WI, USA). 1,2-Dibromoethane, azidotrimethylsilane $\left(\mathrm{Me}_{3} \mathrm{SiN}_{3}\right), 2$,2'-(ethylenedioxy)bis(ethylamine), and propargyl alcohol were purchased from Tokyo Chemical Industry (TCI, Tokyo, Japan). 1-Bromohexane and ethyl 2-bromopropionate were obtained from Kanto Kagaku (Tokyo, Japan). Prop-2-yn-1-yl 2-bromopropanoate [12], (S)-2,5-dibromo-3-(3,7-dimethyloctyl)thiophene ((S)-1a) [13], and 2,5-dibromo-3-hexylthiophene (1b) [14] were prepared according to previously reported methods.

\subsection{Instruments}

NMR spectra were recorded on an NM-LA400FT (JEOL, Tokyo, Japan; $400 \mathrm{MHz}$ for ${ }^{1} \mathrm{H}$ ) or EX270 (JEOL; $270 \mathrm{MHz}$ for ${ }^{1} \mathrm{H}$ ) spectrometer in $\mathrm{CDCl}_{3}$ using TMS as the internal standard. IR spectra were recorded with a JASCO Fourier Transform IR-460 spectrophotometer (Hachioji, Japan). Absorption and CD spectra were measured in a $1.0 \mathrm{~mm}$ quartz cell on a JASCO V-570 spectrophotometer and a JASCO J-725 spectropolarimeter, respectively. The temperature was controlled using a JASCO PTC-348WI apparatus. Size exclusion chromatography (SEC) measurements were performed with a JASCO PU-2080 liquid chromatograph equipped with a UV-vis (Jasco UV-970) detector at $40{ }^{\circ} \mathrm{C}$. The temperature was controlled using a JASCO CO-965 column oven. A Tosoh TSKgel Multipore $\mathrm{X}_{\mathrm{XL}}-\mathrm{M}$ column (30 cm; Tokyo, Japan) was used for SEC measurements using THF as the eluent at a flow rate of $1.0 \mathrm{~mL} / \mathrm{min}$. Molecular weight calibration curves were obtained using polystyrene standards (Tosoh). Dynamic light scattering (DLS) measurements were recorded with a Beckman Coulter N5 instrument (Brea, CA, USA). 


\subsection{Synthesis}

\subsubsection{Synthesis of Amphiphilic Block Copolymers}

Amphiphilic block copolymers (S)-poly-1a- $b$-poly-3 and poly-1b- $b$-poly-3 were synthesized using the route shown in Scheme 2.

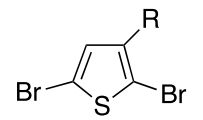

(S)-1a: $R=R^{1}$ 1b: $R=R^{2}$

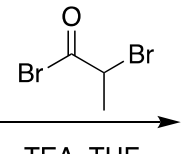

TEA, THF

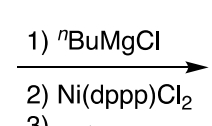

3)

$\widehat{\mathrm{MgBr}}$<smiles></smiles>

(S)-poly-1a-Br poly-1b-Br

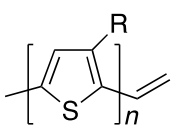

(S)-poly-1a: $\mathrm{R}=\mathrm{R}^{1}, n=49$ poly-1b: $\mathrm{R}=\mathrm{R}^{2}, n=47$

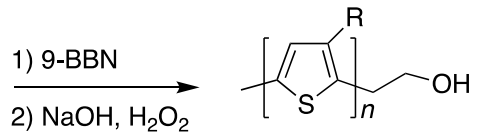

(S)-poly-1a-OH poly-1b-OH<smiles>C=CC(=O)OC(C)(C)C</smiles><smiles>C#CCOC(=O)C(Br)C(C)Br</smiles>

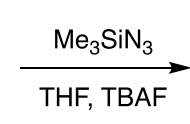
THF, TBAF

(S)-poly-1a- $\mathrm{N}_{3}: \mathrm{R}=\mathrm{R}^{1}, n=49$ poly-1b- $\mathrm{N}_{3}: \mathrm{R}=\mathrm{R}^{2}, n=47$ poly-1b- $\mathrm{N}_{3}: \mathrm{R}=\mathrm{R}^{2}, n=47$

$+$

poly-2, $m=72$

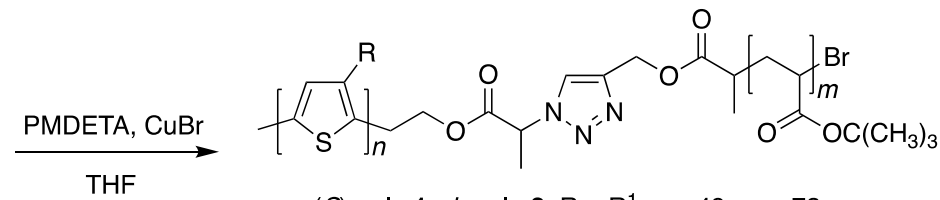

(S)-poly-1a-b-poly-2: $\mathrm{R}=\mathrm{R}^{1}, n=49, m=72$ poly-1b-b-poly-2: $\mathrm{R}=\mathrm{R}^{2}, n=47, m=72$

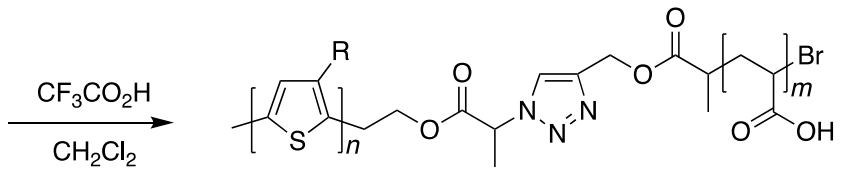

(S)-poly-1a- $b$-poly-3: $\mathrm{R}=\mathrm{R}^{1}, n=49, m=72$ poly-1b-b-poly-3: $\mathrm{R}=\mathrm{R}^{2}, n=47, m=72$

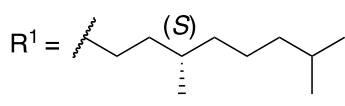

$\mathrm{R}^{2}=\mathrm{N}^{2}$

Scheme 2. Synthesis of amphiphilic block copolymers (S)-poly-1a-b-poly-3 and poly-1b- $b$-poly-3.

Synthesis of (S)-poly-1a: (S)-1a was polymerized according to the procedure of McCullough [15,16]. Under dry nitrogen, $2 \mathrm{M} n$-butylmagnesium chloride in THF was slowly added to the THF solution $(10 \mathrm{~mL})$ of $(S)-1 \mathrm{a}(2.0 \mathrm{~g}, 5.3 \mathrm{mmol})$ using a syringe. After stirring the mixture for $2.5 \mathrm{~h}$ at room temperature (rt), a suspension of $\mathrm{Ni}(\mathrm{dppp}) \mathrm{Cl}_{2}(0.061 \mathrm{~g}, 0.11 \mathrm{mmol})$ in THF $(38 \mathrm{~mL})$ was added, followed by $1 \mathrm{M}$ vinylmagnesium bromide in THF $(1.5 \mathrm{~mL}, 1.5 \mathrm{mmol})$, and the resulting mixture was stirred for $10 \mathrm{~min}$. The solvent was then evaporated, the mixture poured into a large amount of methanol, and the resulting polymer collected by centrifugation, washed with methanol, and dried in vacuo. A Soxhlet purification was performed using methanol, hexane, and chloroform sequentially to obtain (S)-poly-1a as a green solid (0.53 g, 44\% yield). ${ }^{1} \mathrm{H} \mathrm{NMR}\left(270 \mathrm{MHz}, \mathrm{CDCl}_{3}, \mathrm{rt}\right): \delta 6.97(\mathrm{~s}, 1 \mathrm{H}$, $\mathrm{Ar}-\mathrm{H}), 2.68-2.92\left(\mathrm{~m}, \mathrm{Ar}-\mathrm{CH}_{2}\right), 1.12-1.82\left(\mathrm{~m}, 10 \mathrm{H}, 4 \mathrm{CH}_{2}\right.$ and $\left.2 \mathrm{CH}\right), 0.98\left(\mathrm{~d}, J=5.9 \mathrm{~Hz}, 3 \mathrm{H}, \mathrm{CH}_{3}\right), 0.86$ $\left(\mathrm{d}, J=6.5 \mathrm{~Hz}, 6 \mathrm{H}, 2 \mathrm{CH}_{3}\right)$. From the ${ }^{1} \mathrm{H}$ NMR spectrum (Figure $\mathrm{S} 1$ ), the degree of polymerization (DP) and the number average molecular weight $\left(M_{\mathrm{n}}\right)$ were determined as 49 and $1.1 \times 10^{4}$, respectively, based on the integral ratio of the proton signal on the thiophene ring in the repeat unit to the proton 
signals of the vinyl groups at the ends. The $M_{\mathrm{n}}$ and its distribution $\left(M_{\mathrm{w}} / M_{\mathrm{n}}\right)$ were estimated to be $1.3 \times 10^{4}$ and 1.2, respectively, by SEC using polystyrene standards with THF as the eluent at $40^{\circ} \mathrm{C}$.

Synthesis of poly-1b: poly-1b was synthesized using the same method as $(S)$-poly-1a but from $\mathbf{1} \mathbf{b} .{ }^{1} \mathrm{H}$ NMR $\left(270 \mathrm{MHz}, \mathrm{CDCl}_{3}, \mathrm{rt}\right): \delta 6.98(\mathrm{~s}, 1 \mathrm{H}, \mathrm{Ar}-H), 2.80\left(\mathrm{t}, J=7.6 \mathrm{~Hz}, 2 \mathrm{H}, \mathrm{Ar}-\mathrm{CH}_{2}\right), 1.65-1.73(\mathrm{~m}, 2 \mathrm{H}$, Ar- $\left.\mathrm{CH}_{2} \mathrm{CH}_{2}\right), 1.25-1.50\left(\mathrm{~m}, 6 \mathrm{H}, 3 \mathrm{CH}_{2}\right), 0.91\left(\mathrm{t}, J=6.7 \mathrm{~Hz}, 3 \mathrm{H}, \mathrm{CH}_{3}\right)$. The DP and $M_{\mathrm{n}}$ were determined to be 47 and $7.8 \times 10^{3}$, respectively, by ${ }^{1} \mathrm{H}$ NMR analysis. The $M_{\mathrm{n}}$ and $M_{\mathrm{w}} / M_{\mathrm{n}}$ estimated using SEC were $1.1 \times 10^{4}$ and 1.4 , respectively.

Synthesis of (S)-poly-1a-OH: Under dry nitrogen, 0.5 M 9-BBN in THF (11.3 mL, $5.7 \mathrm{mmol})$ was slowly added to a THF solution $(60 \mathrm{~mL})$ of $(S)$-poly-1a $(0.51 \mathrm{~g}$, $0.046 \mathrm{mmol})$ using a syringe, and the mixture was stirred for $24 \mathrm{~h}$ at $40^{\circ} \mathrm{C}$. Next, $6 \mathrm{M} \mathrm{NaOH}(6.6 \mathrm{~mL})$ was added at $\mathrm{rt}$ and the mixture was stirred for $15 \mathrm{~min}$. Thirty percent $\mathrm{H}_{2} \mathrm{O}_{2}(6.6 \mathrm{~mL})$ was then added and the mixture was stirred for $24 \mathrm{~h}$ at $40{ }^{\circ} \mathrm{C}$. After evaporating the solvent, the mixture was poured into a large amount of methanol/water $(1 / 1, v / v)$, and the resulting polymer was collected by centrifugation, washed with methanol/water $(1 / 1, v / v)$, and dried in vacuo. A Soxhlet purification was performed using methanol to obtain (S)-poly-1a-OH as a green solid (0.50 $\mathrm{g}, 99 \%$ yield).

Synthesis of (S)-poly-1a-Br: Under dry nitrogen, TEA (4.5 mL, $32.2 \mathrm{mmol})$ was slowly added to the THF solution $(48 \mathrm{~mL})$ of $(S)$-poly-1a-OH $(0.48 \mathrm{~g}, 0.048 \mathrm{mmol})$ with a syringe, and the mixture was stirred for $15 \mathrm{~min}$ at $40^{\circ} \mathrm{C}$. After the addition of 2-bromopropionyl bromide $(3.6 \mathrm{~mL}, 34.0 \mathrm{mmol})$, the mixture was stirred for $24 \mathrm{~h}$. After the solvent was evaporated, the mixture was poured into a large amount of methanol, and the resulting polymer was collected by centrifugation, washed with methanol, and dried in vacuo. A Soxhlet purification was performed using methanol to obtain (S)-poly-1a-Br as a green solid (0.51 g, quantitative yield).

Synthesis of (S)-poly-1a- $N_{3}$ : Under dry nitrogen, $1.0 \mathrm{M}$ TBAF in THF $(190 \mu \mathrm{L}, 0.19 \mathrm{mmol})$ was slowly added to a THF solution ( $15 \mathrm{~mL})$ of (S)-poly-1a-Br $(0.21 \mathrm{~g}, 0.019 \mathrm{mmol})$ and $\mathrm{Me}_{3} \mathrm{SiN}_{3}(25 \mu \mathrm{L}, 0.19 \mathrm{mmol})$ using a syringe, and the mixture was stirred for $48 \mathrm{~h}$ at rt. After evaporating the solvent, the mixture was poured into a large amount of methanol, and the resulting polymer was collected by centrifugation, washed with methanol, and dried in vacuo. A Soxhlet purification was performed using methanol to obtain (S)-poly-1a- $\mathrm{N}_{3}$ as a green solid (0.192 $\mathrm{g}, 92 \%$ yield).

Synthesis of poly-2: Poly-2 was synthesized according to a literature method [17]. Prop-2-yn-1-yl 2-bromopropanoate ( $78 \mathrm{mg}, 0.041 \mathrm{mmol})$, tert-butyl acrylate $(6.0 \mathrm{~mL}, 40.8 \mathrm{mmol})$, toluene $(6.0 \mathrm{~mL})$, and $\mathrm{CuBr}(58.6 \mathrm{mg}, 0.41 \mathrm{mmol})$ were placed in a dry Schlenk flask under an argon atmosphere. PMDETA $(86 \mu \mathrm{L}, 0.41 \mathrm{mmol})$ was added and the mixture was stirred for $9 \mathrm{~h}$ at $80^{\circ} \mathrm{C}$. The solution was extracted with chloroform and the organic layer was washed with water until the blue color of copper had completely disappeared and then dried over $\mathrm{Na}_{2} \mathrm{SO}_{4}$. After evaporating the solvent, the obtained product was dissolved in a small amount of methanol, poured into a large amount of methanol/water $(7 / 3, v / v)$ at $0{ }^{\circ} \mathrm{C}$, and the resultant precipitated polymer was washed with methanol/water $(7: 3, v / v)$ and dried in vacuo to afford poly-2 as a white solid ( $2.19 \mathrm{~g}, 42 \%$ yield). ${ }^{1} \mathrm{H}$ NMR $\left(400 \mathrm{MHz}, \mathrm{CDCl}_{3}, \mathrm{rt}\right)$ : $\delta 2.15-2.35$ (br, $1 \mathrm{H}, \mathrm{CH}$ of the polymer backbone), 1.74-1.90 (br, meso $\mathrm{CH}_{2}$ of the polymer backbone), 1.20-1.60 (br, meso and racemo $\mathrm{CH}_{2}$ of the polymer backbone), $1.20-1.50\left(\mathrm{br}, 3 \mathrm{CH}_{3}\right)$. The DP and $M_{\mathrm{n}}$ were determined as 72 and $9.2 \times 10^{3}$, respectively, by ${ }^{1} \mathrm{H}$ NMR analysis based on the integral ratio of the proton signal of the methine group in the repeat unit to the proton signals of the methylene group next to the terminal ethynyl group. The $M_{\mathrm{n}}$ and $M_{\mathrm{w}} / M_{\mathrm{n}}$ were also estimated to be $9.1 \times 10^{3}$ and 1.3 , respectively, by SEC using polystyrene standards in THF as the eluent at $40{ }^{\circ} \mathrm{C}$.

Synthesis of (S)-poly-1a-b-poly-2: In a dry Schlenk flask, $\mathrm{CuBr}(6.7 \mathrm{mg}, 0.046 \mathrm{mmol})$ was added to a THF solution $(2 \mathrm{~mL})$ of $(S)$-poly-1a- $\mathrm{N}_{3}(0.050 \mathrm{~g}, 0.0046 \mathrm{mmol})$, poly-2 $(0.11 \mathrm{~g}, 0.012 \mathrm{mmol})$, and PMDETA $(10 \mu \mathrm{L}, 0.046 \mathrm{mmol})$ under dry nitrogen, and the mixture was stirred for $4 \mathrm{~h}$ at $\mathrm{rt}$. After evaporating the solvent, the mixture was poured into a large amount of methanol, and the resulting polymer was collected by centrifugation, washed with methanol, and dried in vacuo to obtain (S)-poly-1a- $b$-poly-2 
as a purple solid $\left(75 \mathrm{mg}, 82 \%\right.$ yield). IR $\left(\mathrm{KBr}, \mathrm{cm}^{-1}\right)$ : 1727 ( $\left.v_{\mathrm{C}=\mathrm{O} \text { of ester }}\right) .{ }^{1} \mathrm{H} \mathrm{NMR}\left(400 \mathrm{MHz}, \mathrm{CDCl}_{3}, \mathrm{rt}\right)$ : $\delta 6.98(\mathrm{~s}, 1 \mathrm{H}, \mathrm{Ar}-\mathrm{H}), 2.81\left(\mathrm{br}, 2 \mathrm{H}, \mathrm{Ar}-\mathrm{CH}_{2}\right), 2.27(\mathrm{br}, 1 \mathrm{H}, \mathrm{CH}$ of poly (acrylic acid)), 1.10-1.90 (m, 21H), $0.98\left(\mathrm{~d}, 3 \mathrm{H}, \mathrm{CH}_{3}\right), 0.87\left(\mathrm{~d}, 6 \mathrm{H}, 2 \mathrm{CH}_{3}\right)$.

Synthesis of (S)-poly-1a-b-poly-3: Under dry nitrogen, trifluoroacetic acid $(0.1 \mathrm{~mL}, 1.35 \mathrm{mmol})$ was added to a $\mathrm{CHCl}_{3} / 1,4$-dioxane $(5 / 2, v / v)$ solution $(4.2 \mathrm{~mL})$ of $(S)$-poly-1a-b-poly-2 $(0.061 \mathrm{~g}, 0.22 \mathrm{mmol})$, and the mixture was stirred for $24 \mathrm{~h}$ at $40{ }^{\circ} \mathrm{C}$. After the solvent was evaporated, the mixture was washed with methanol and dried in vacuo to obtain (S)-poly-1a- $b$-poly-3 as a black solid $(43 \mathrm{mg}, 88 \%$ yield). IR $\left(\mathrm{KBr}, \mathrm{cm}^{-1}\right): 1727$ ( $\left.v_{\mathrm{C}=\mathrm{O} \text { of carboxylic acid }}\right) \cdot{ }^{1} \mathrm{H}$ NMR $\left(400 \mathrm{MHz}, \mathrm{CDCl}_{3}, \mathrm{rt}\right): \delta 6.98(\mathrm{~s}, 1 \mathrm{H}, \mathrm{Ar}-\mathrm{H})$, $2.76\left(\mathrm{br}, 2 \mathrm{H}, \mathrm{Ar}-\mathrm{CH}_{2}\right), 2.05$ (br, $1 \mathrm{H}, \mathrm{CH}$ of poly(acrylic acid)), 1.05-1.80 (m, 12H), $0.97\left(\mathrm{~d}, 3 \mathrm{H}, \mathrm{CH}_{3}\right)$, $0.86\left(\mathrm{~d}, 6 \mathrm{H}, 2 \mathrm{CH}_{3}\right)$.

Synthesis of poly-1b-b-poly-3: Poly-1b-b-poly-3 was synthesized using the same method as (S)-poly-1a-b-poly-3 through the click coupling of poly-1b and poly-2 followed by hydrolysis of the tert-butyl ester groups. IR $\left(\mathrm{KBr}, \mathrm{cm}^{-1}\right)$ : $1727\left(v_{\mathrm{C}=\mathrm{O} \text { of carboxylic acid }}\right){ }^{1} \mathrm{H}$ NMR $\left(400 \mathrm{MHz}, \mathrm{CDCl}_{3}, \mathrm{rt}\right)$ : $\delta 6.98(\mathrm{~s}, 1 \mathrm{H}, \mathrm{Ar}-\mathrm{H}), 2.81\left(\mathrm{br}, 2 \mathrm{H}, \mathrm{Ar}-\mathrm{CH}_{2}\right), 2.05$ (br, 1H, $\mathrm{CH}$ of poly(acrylic acid)), 1.10-1.90 (m, 10H), $0.92\left(\mathrm{br}, 3 \mathrm{H}, \mathrm{CH}_{3}\right)$.

\subsubsection{Crosslinking of (S)-Poly-1a-b-poly-3 Micelles}

To a THF solution (17 mL) of (S)-poly-1a-b-poly-3 $(5.0 \mathrm{mg}, 22 \mu \mathrm{mol})$ was added water $(17 \mathrm{~mL})$ at a rate of $0.2 \mathrm{~mL} / \mathrm{min}$ using a syringe pump. After removing THF in vacuo, 2,2'-(ethylenedioxy)bis(ethylamine) $(829 \mu \mathrm{g}, 5.6 \mu \mathrm{mol})$ in water $(170 \mu \mathrm{L})$ was added slowly and the mixture was stirred for $1 \mathrm{~h}$ at rt. Next, an aqueous solution of 1-[3'-(dimethylamino)propyl]-3-ethylcarbodiimide methiodide $(3.3 \mathrm{mg}, 11 \mu \mathrm{mol}, 3.3 \mathrm{~mL}$ ) was added at a rate of $0.2 \mathrm{~mL} / \mathrm{min}$ using a syringe pump. The resulting polymer was purified using a dialysis membrane (MWCO 3500) in water for 4 days. After removing the water by freeze drying, crosslinked micelles of (S)-poly-1a-b-poly-3 were obtained.

\section{Results and Discussion}

\subsection{Synthesis of Amphiphilic Block Copolymers}

Regioregular HT chiral ((S)-poly-1a- $\mathrm{N}_{3}$ ) and achiral (poly-1 $\left.\mathbf{b}-\mathrm{N}_{3}\right)$ PTs possessing a terminal azide group were synthesized according to a literature method (Scheme 2) [15-20]. Vinyl-terminated PTs (S)-poly-1a and poly-1b were first synthesized from the corresponding 2,5-dibromothiophene derivatives using a Grignard metathesis method (GRIM) with n-butylmagnesium chloride, $\mathrm{Ni}(\mathrm{dppp}) \mathrm{Cl}_{2}$, and vinylmagnesium bromide as the end-capping reagent $[15,16,18]$. Based on the integral ratio of the signal attributed to the proton at the 4-position of the thiophene ring to that attributed to the terminal vinyl protons in the ${ }^{1} \mathrm{H}$ NMR spectra of (S)-poly-1a and poly-1 $\mathbf{b}$, the average degree of polymerization (DP) and the number average molecular weight $\left(M_{n}\right)$ were determined as 49 and $1.1 \times 10^{4}\left((S)\right.$-poly-1a), and 47 and $7.8 \times 10^{3} \mathrm{Da}$ (poly-1b), respectively (Figure S1). The terminal vinyl groups of (S)-poly-1a and poly-1 $\mathbf{b}$ were first converted into hydroxyethyl groups by hydroboration-oxidation $((S)-$ poly-1a-OH and poly-1 $\mathbf{b}-\mathrm{OH})$ and the resulting hydroxy groups were then converted to bromoesters by reacting with 2-bromopropionyl bromide ((S)-poly-1a-Br and poly-1b-Br) $[15,16,18]$. The terminal bromide groups of $(S)$-poly-1a-Br and poly-1b-Br were further converted into azide groups by nucleophilic substitution with $\mathrm{Me}_{3} \mathrm{SiN}_{3}$ to give (S)-poly-1a- $\mathrm{N}_{3}$ and poly- $\mathbf{1 b}-\mathrm{N}_{3}$. Conversion of the terminal groups was confirmed in each step by ${ }^{1} \mathrm{H}$ NMR spectroscopy (see Figures S1-S4).

Poly(tert-butyl acrylate) with a terminal ethynyl group (poly-2) was synthesized by the atom transfer radical polymerization (ATRP) of tert-butyl acrylate using copper(I) bromide as the catalyst and prop-2-yn-1-yl 2-bromopropanoate as the initiator in toluene according to a previously reported method (Scheme 2) $[17,21,22]$. The DP and $M_{n}$ of poly-2 were determined as 72 and $9.2 \times 10^{3} \mathrm{Da}$, 
respectively, based on the integral ratio of the methine proton signal in the repeat unit at $2.2 \mathrm{ppm}$ to the methylene proton signals next to the terminal ethynyl group at $4.65 \mathrm{ppm}$ in the ${ }^{1} \mathrm{H}$ NMR spectrum of poly-2 (Figure S5).

Chiral (S)-poly-1a- $\mathrm{N}_{3}$ and poly-2 were transformed into the corresponding block copolymer ((S)-poly-1a-b-poly-2) connected to a triazole ring by a Huisgen cycloaddition using CuBr and PMDETA as the catalyst $[17,23-25]$. Figure 1a shows SEC chromatograms of the obtained (S)-poly-1a- $b$-poly-2 and precursor polymers (S)-poly-1a- $\mathrm{N}_{3}$ and poly-2). The peak of (S)-poly-1a-b-poly-2 was shifted to a higher molecular weight than the peaks of both (S)-poly-1a- $\mathrm{N}_{3}$ and poly-2, while maintaining the unimodal shape. In the ${ }^{1} \mathrm{H}$ NMR spectrum of (S)-poly-1a-b-poly-2, peaks attributed to the triazole ring were clearly observed at around 5.0-5.6 ppm and 7.7-7.9 ppm, suggesting that the block copolymer was successfully formed through a click reaction. (Figure 1b). Hydrolysis of the tert-butyl group of (S)-poly-1a-b-poly-2 with trifluoroacetic acid afforded the corresponding amphiphilic block copolymer with a poly(acrylic acid) chain ((S)-poly-1a-b-poly-3). The hydrolysis of the tert-butyl group was confirmed as complete by the disappearance of the peak attributed to the tert-butyl group in the ${ }^{1} \mathrm{H}$ NMR spectrum (Figure S6). Similarly, an amphiphilic block copolymer containing an achiral PT chain (poly-1b-b-poly-3) was prepared by the click reaction of poly-1b with poly-2 followed by hydrolysis of the tert-butyl group with trifluoroacetic acid (Figures S7 and S8).

(a)

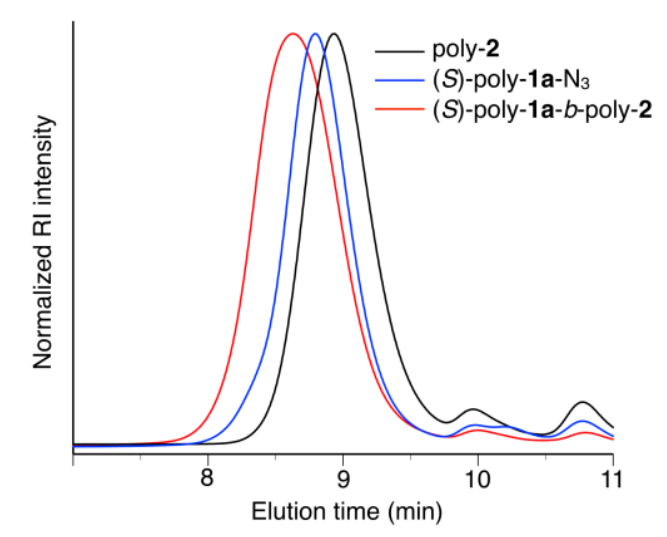

(b)

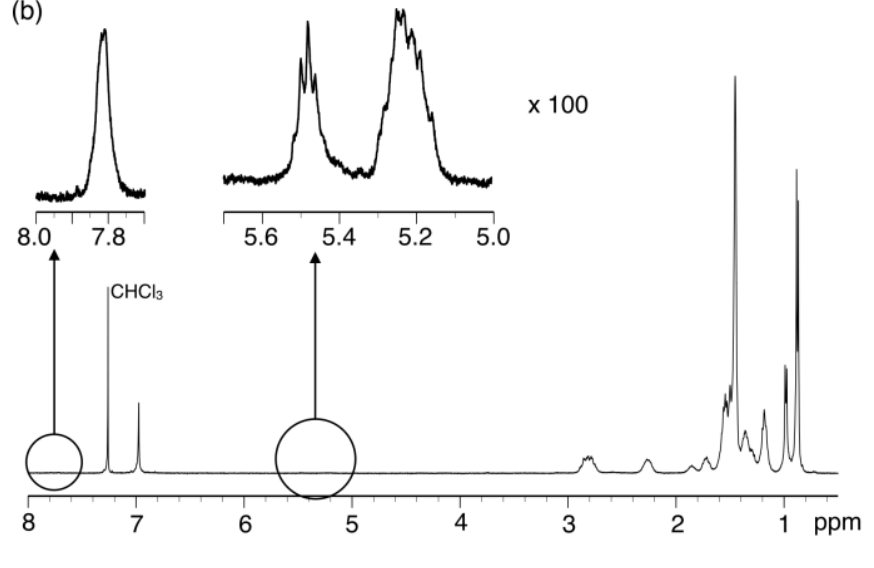

Figure 1. Results of the click reaction of (S)-poly-1a- $\mathrm{N}_{3}$ with poly-2: (a) size exclusion chromatography (SEC) traces of (S)-poly-1a- $b$-poly-2, poly-2, and (S)-poly-1a- $\mathrm{N}_{3}$ in tetrahydrofuran (THF) at $40{ }^{\circ} \mathrm{C}$ (PSt standard); (b) ${ }^{1} \mathrm{H}$ NMR spectrum of (S)-poly-1a-b-poly-2 in $\mathrm{CDCl}_{3}$ at rt.

\subsection{Chiroptical Properties}

The amphiphilic block copolymer (S)-poly-1a- $b$-poly-3 was expected to form micelles by adding water to a THF solution of (S)-poly-1a-b-poly-3 at a flow rate of $0.1 \mathrm{~mL} / \mathrm{min}$ using a syringe pump because (S)-poly-1a-b-poly-3 is insoluble in water but soluble in THF. Figure 2a shows the CD and absorption spectra of (S)-poly-1a-b-poly-3 in THF with increasing amounts of water. The CD spectrum of (S)-poly-1a- $b$-poly-3 in THF showed almost no CD in the wavelength region of the PT backbone absorption, and similar spectra were observed at water contents of up to $70 \%$. However, at a water content of $80 \%$, the peak of the absorption spectrum was significantly redshifted, the solution color significantly changed from orange to purple, and an intense split-type positive Cotton effect was observed in the $\pi-\pi^{*}$ transition region of the PT main chain. At a water content of $90 \%$, the absorption spectra of (S)-poly-1a-b-poly-3 showed a further bathochromic shift with a clear isosbestic point at $477 \mathrm{~nm}$ and a further increase in CD intensity. The solution remained homogeneous, even after the removal of THF under reduced pressure, and the CD and absorption spectra in water were almost the same as those at a water content of $90 \%$. These results indicated that the amphiphilic block copolymer (S)-poly-1a-b-poly-3 formed micelles in water, with the hydrophobic PT chain 
forming a supramolecular chiral aggregate in the micelle cores. To investigate the size of the micelle comprising (S)-poly-1a-b-poly-3, DLS measurements were conducted in water and indicated the formation of near-monodisperse micelles with a hydrodynamic radius $\left(R_{\mathrm{h}}\right)$ of approximately $50 \mathrm{~nm}$ (see Figure S9) [6].
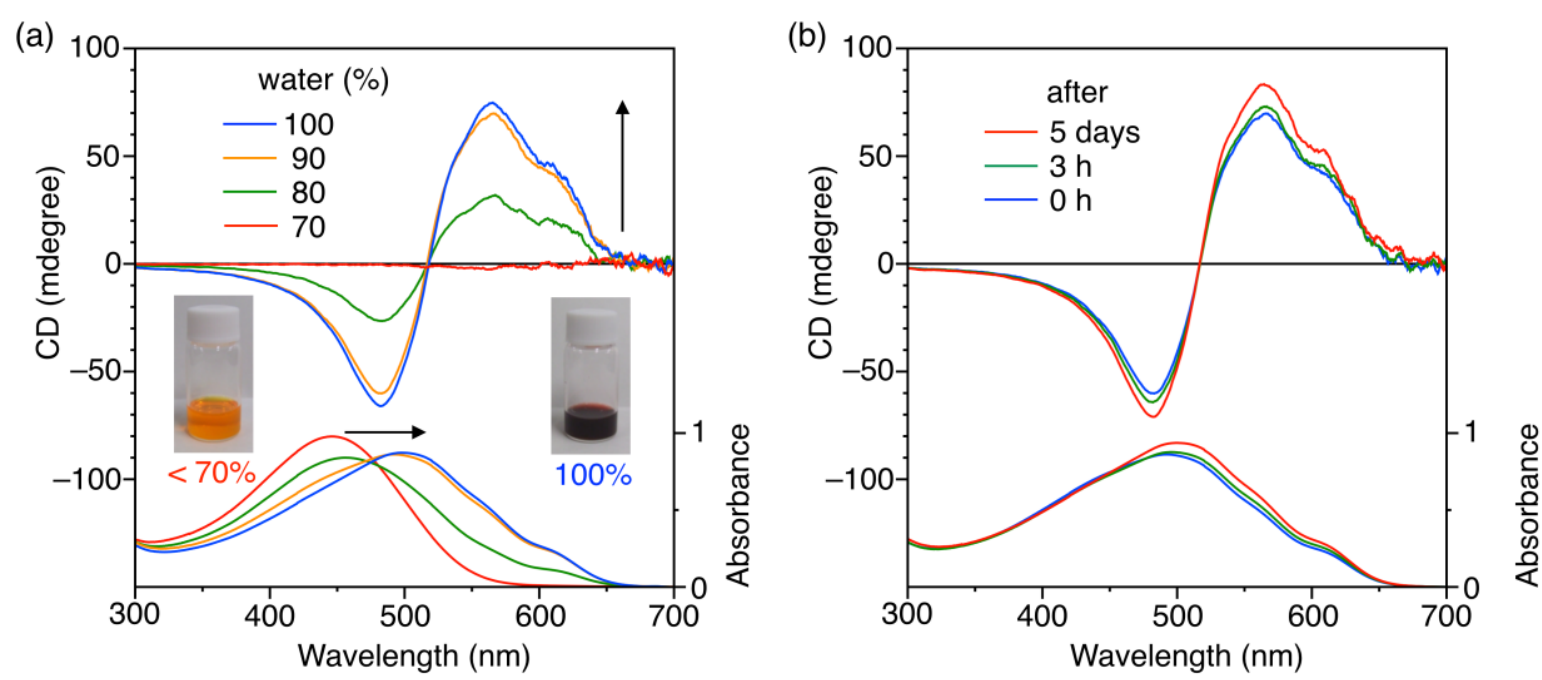

Figure 2. Circular dichroism (CD) and absorption spectra of (S)-poly-1a- $b$-poly-3 in THF/water at rt: (a) effect of THF in water; (b) time-dependent change in water. [(S)-poly-1a- $b$-poly-3] $=0.5 \mathrm{mg} / \mathrm{mL}$.

Figure $2 \mathrm{~b}$ shows the time-dependent $\mathrm{CD}$ and absorption spectral changes of (S)-poly-1a- $b$-poly-3 in water. The $C D$ intensity slightly increased and was accompanied by a slight redshift of the absorption peak after 5 days, and no precipitation was observed, even after 1 week. In contrast, chiral aggregates derived from chiral thiophene homopolymer $((S)$-poly-1a) with only a hydrophobic chain in a poor solvent system $\left(\mathrm{CHCl}_{3} /\right.$ methanol $\left.(1 / 1, v / v)\right)$ at $\mathrm{rt}$ showed a gradual decrease in the $\mathrm{CD}$ intensity with time (see Figure S10), with the CD intensity decreasing by more than half the initial value after $24 \mathrm{~h}$ due to precipitation of the chiral aggregates. This demonstrates that inducing aggregate formation in the micelle core is a useful method for obtaining chiral supramolecular aggregates that are stable in solution for long periods.

The chiral amplification behavior of chiral aggregate formation of (S)-poly-1a-b-poly-3 in the micelle core was also investigated. In this experiment, micelles were formed from mixtures of chiral (S)-poly-1a- $b$-poly-3 and achiral poly-1b-b-poly-3 at various feed ratios in THF/water $(9: 1, v / v)$ and $\mathrm{CD}$ and absorption spectra of these micelles were measured (Figure $3 a)$. Figure $3 b$ shows plots of the observed CD intensity at $565 \mathrm{~nm}$ against the feed ratio of chiral (S)-poly-1a- $b$-poly-3 and a strong negative nonlinear relationship was observed [26], where the observed CD intensity was much lower than predicted by a linear relationship (dotted line in Figure 3b). This result suggested that cooperative interactions between the chiral PT chains played an important role in chiral aggregate formation in the micelle core. Similar negative nonlinear effects have been reported for the formation of chiral supramolecular aggregates of chiral PT chains in a poor solvent $[27,28]$. 

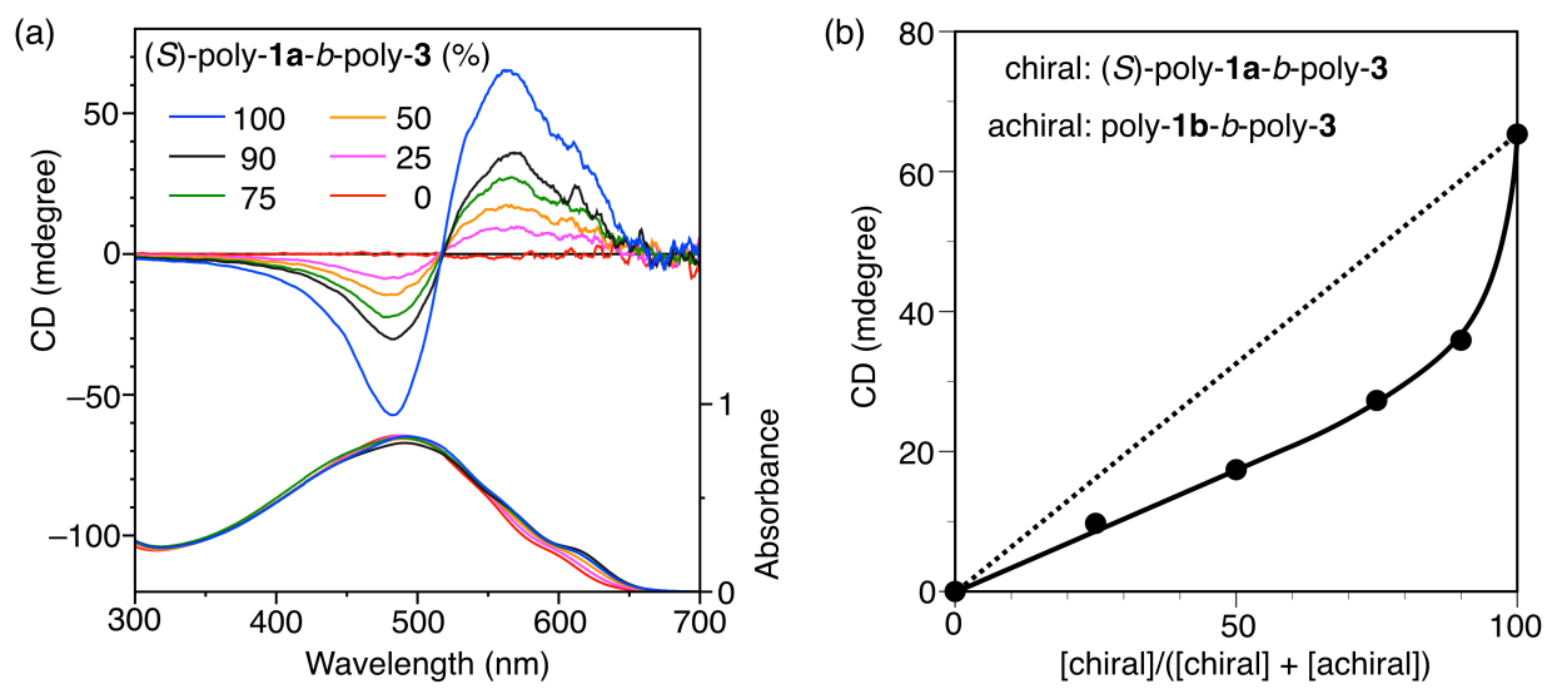

Figure 3. (a) $\mathrm{CD}$ and absorption spectra of aggregates consisting of (S)-poly-1a- $b$-poly-3 and poly-1b-b-poly-3; (b) Plots of CD intensity at around $565 \mathrm{~nm}$ for aggregates consisting of (S)-poly-1a- $b$-poly-3 and poly-1b-b-poly-3 in THF $/ \mathrm{H}_{2} \mathrm{O}(9: 1, v / v)$ at rt.

\subsection{Micelle Stabilization through Crosslinking}

The crosslinking of micelles in the shell domain has been reported to lead to the formation of robust nanoparticles known as shell-crosslinked micelles. We performed the shell crosslinking of micelles of (S)-poly-1a-b-poly-3 to determine whether shell crosslinking could increase the stability of the internal chiral aggregate structure formed in the core domain of the micelles. Nominally $50 \%$ of the carboxylic acid groups in the poly(acrylic acid) shell of the micelles of (S)-poly-1a-b-poly-3 were crosslinked using a water-soluble diamine, $2,2^{\prime}$-(ethylenedioxy)bis(ethylamine), as a crosslinker molecule and a water-soluble carbodiimide, 1-[3-(dimethylamino)propyl]-3-ethylcarbodiimide methiodide, as a condensing reagent, according to a reported method (Figure 4a) [11,29,30]. After the reaction and purification by dialysis, shell crosslinking through amide bond formation was confirmed by IR analysis, with new peaks attributed to the amide group observed at around $1650 \mathrm{~cm}^{-1}$ (amide I) and $1560 \mathrm{~cm}^{-1}$ (amide II) in the IR spectrum of the resulting micelle (Figure $4 \mathrm{~b}$ ). Figure 5 shows the $\mathrm{CD}$ and absorption spectra of (S)-poly-1a- $b$-poly-3 in water at various temperatures before and after shell crosslinking. Before shell crosslinking, the CD intensity of the micelles decreased with increasing temperature (Figure 5a). However, after crosslinking, the $\mathrm{CD}$ and absorption spectra of the shell-crosslinked micelles showed almost no change in the CD intensity at any temperature (Figure 5b). This demonstrated that shell crosslinking of the micelle stabilized the chiral supramolecular aggregates of the PT chains formed in the core. 
(a)

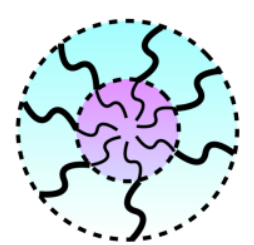

(S)-poly-1a-b-poly-3
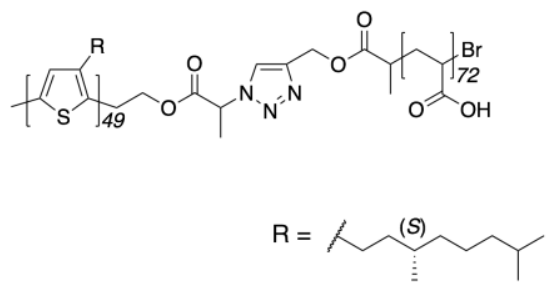
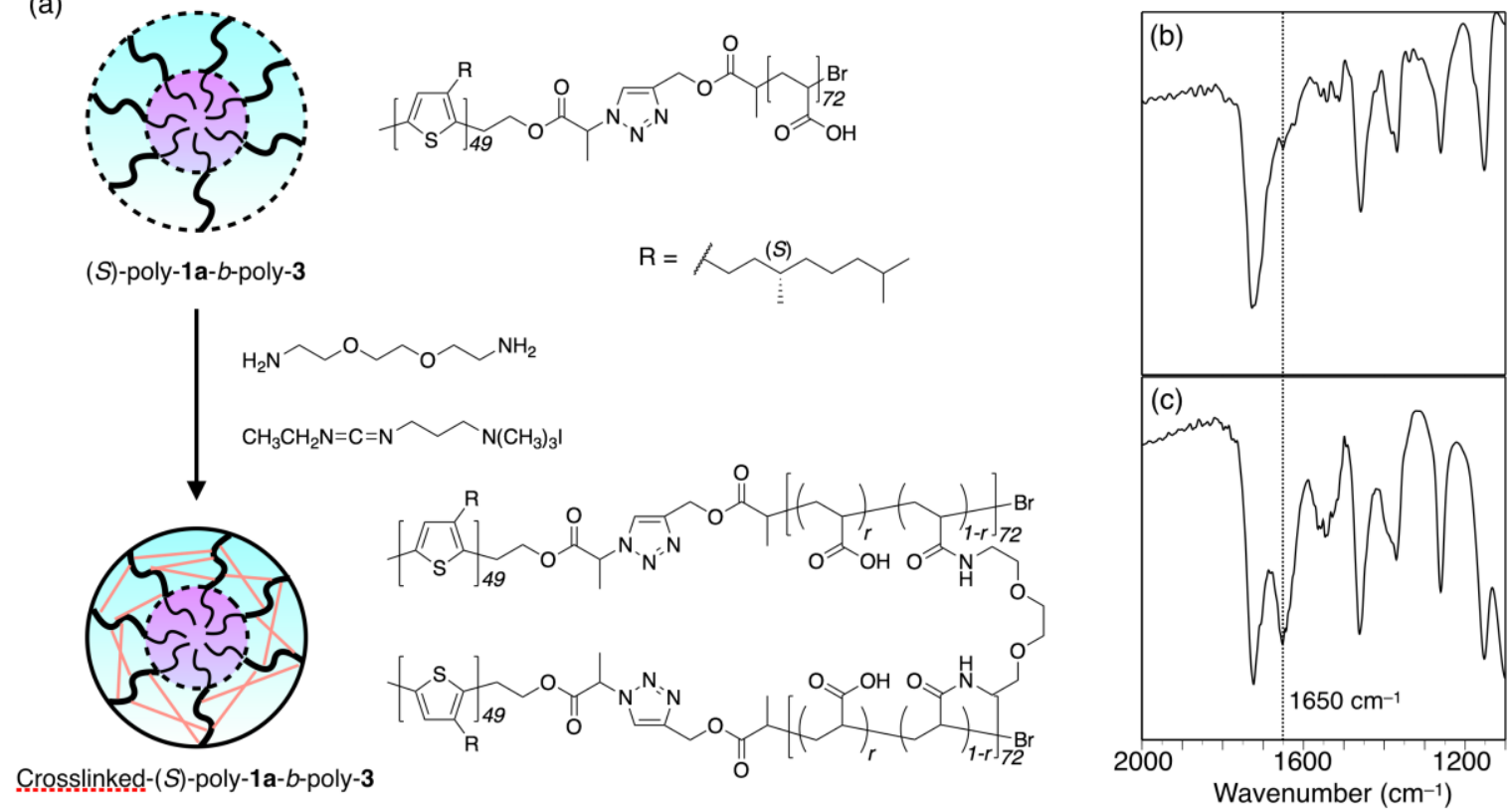

Figure 4. (a) Schematic illustration of shell crosslinking of micelles comprising $(S)$-poly-1a-b-poly-3 and $(\mathbf{b}, \mathbf{c})$ IR spectra of (b) ((S)-poly-1a- $b$-poly-3 and (c) crosslinked-(S)-poly-1a-b-poly-3 at rt.

(a)

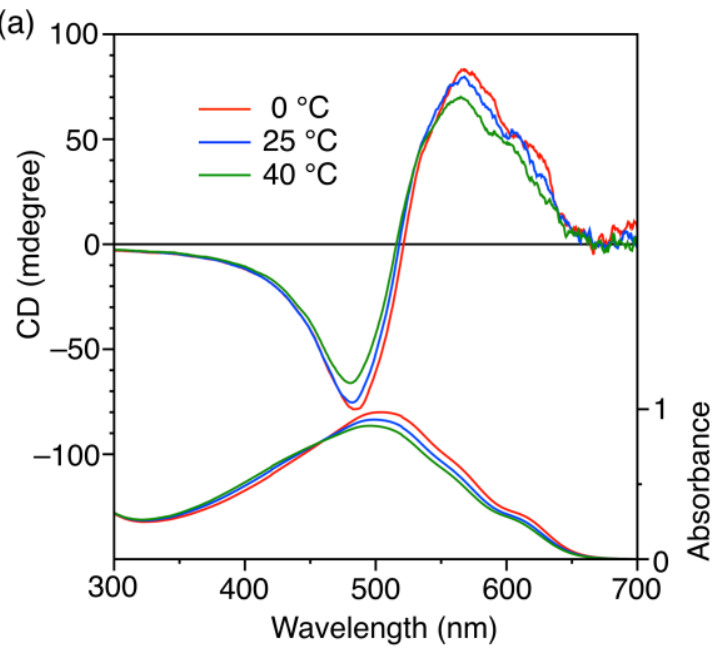

(b)

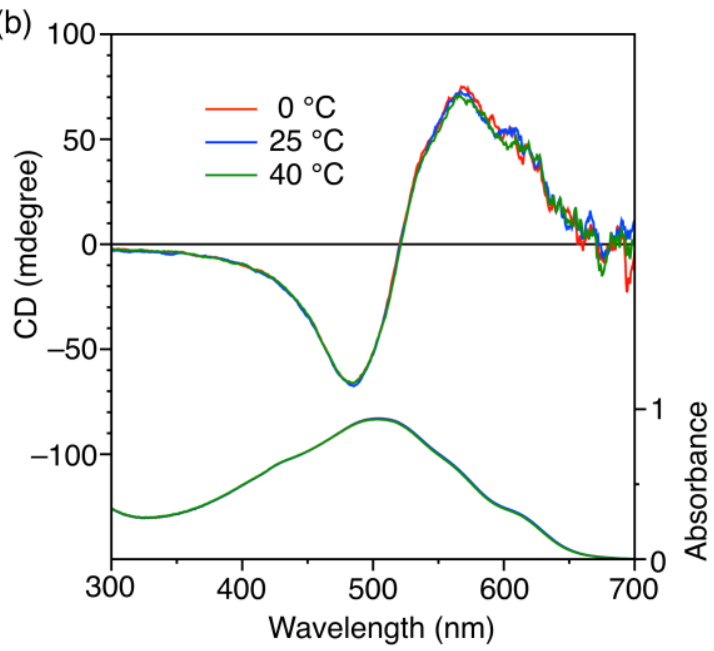

Figure 5. CD and absorption spectra of the micelles comprising (S)-poly-1a-b-poly-3 (a) before and (b) after shell crosslinking in water at various temperatures.

\section{Conclusions}

In conclusion, amphiphilic block copolymers consisting of hydrophobic regioregular chiral or achiral PT chains and a hydrophilic poly(acrylic acid) chain were successfully synthesized using a macromolecular click reaction. The chiroptical properties of micelles of the amphiphilic block copolymers containing the chiral PT block were investigated to evaluate the chiral aggregate formation behavior of the PT chains in micelles. Micelles consisting of poly(acrylic acid) as the shell and optically active PT as the core were generated by self-assembly in water, and chiral supramolecular aggregates were formed in the core that were stable in aqueous solution for long periods without precipitation. Chiral aggregates consisting of chiral (S)-poly-1a- $b$-poly-3 and achiral poly-16- $b$-poly-3 formed in the micelle core showed a negative nonlinear relationship between the observed $C D$ intensity and the feed ratio of the chiral unit. Chiral supramolecular aggregates of PT chains formed in the core 
were highly stabilized by shell crosslinking of the micelles, as evidenced by the CD intensity showing almost no change with increasing temperature. The shell-crosslinked robust nanoparticles possessing chiral supramolecular aggregates in the hydrophobic core could potentially be used as enantioselective sensors and chiral catalysts for asymmetric synthesis. Studies of such applications are currently in progress.

Supplementary Materials: The following are available online at http:/ / www.mdpi.com/2073-4360/10/7/718/s1, Figure S1: ${ }^{1} \mathrm{H}$ NMR spectrum of (S)-poly-1a, Figure S2: ${ }^{1} \mathrm{H}$ NMR spectrum of (S)-poly-1a-OH, Figure S3: ${ }^{1} \mathrm{H}$ NMR spectrum of (S)-poly-1a-Br, Figure S4: ${ }^{1} \mathrm{H}$ NMR spectrum of $(S)$-poly-1a- $\mathrm{N}_{3}$, Figure S5: ${ }^{1} \mathrm{H}$ NMR spectrum of poly-2, Figure S6: ${ }^{1} \mathrm{H}$ NMR spectrum of (S)-poly-1a-b-poly-3, Figure S7: ${ }^{1} \mathrm{H}$ NMR spectrum of poly-1b-b-poly-2, Figure S8: ${ }^{1} \mathrm{H}$ NMR spectrum of poly-1b-b-poly-3, Figure S9: DLS data of the micelles comprising (S)-poly-1a- $b$-poly-3, Figure S10: Time-dependent CD intensity change of (S)-poly-1a in $\mathrm{CHCl}_{3} / \mathrm{MeOH}(1 / 1, v / v)$.

Author Contributions: K.M. conceived and designed the experiments; S.N. and D.H. performed the experiments; K.M. and S.K. analyzed the data; K.M. and D.H. wrote the paper; All of the authors discussed the results and edited the manuscript.

Funding: This work was funded in part by JSPS KAKENHI Grant No. 16H04154 and 17H05361 (Coordination Asymmetry).

Conflicts of Interest: The authors declare no conflicts of interest.

\section{References}

1. Langeveld-Voss, B.M.W.; Janssen, R.A.J.; Meijer, E.W. On the origin of optical activity in polythiophenes. J. Mol. Struct. 2000, 521, 285-301. [CrossRef]

2. Hoeben, F.J.M.; Jonkheijm, P.; Meijer, E.W.; Schenning, A.P.H.J. About supramolecular assemblies of pi-conjugated systems. Chem. Rev. 2005, 105, 1491-1546. [CrossRef] [PubMed]

3. Kane-Maguire, L.A.P.; Wallace, G.G. Chiral conducting polymers. Chem. Soc. Rev. 2010, 39, 2545-2576. [CrossRef] [PubMed]

4. Goto, H.; Yashima, E.; Okamoto, Y. Unusual solvent effects on chiroptical properties of an optically active regioregular polythiophene in solution. Chirality 2000, 12, 396-399. [CrossRef]

5. Goto, H.; Yashima, E. Electron-induced switching of the supramolecular chirality of optically active polythiophene aggregates. J. Am. Chem. Soc. 2002, 124, 7943-7949. [CrossRef] [PubMed]

6. Goto, H.; Okamoto, Y.; Yashima, E. Solvent-induced chiroptical changes in supramolecular assemblies of an optically active, regioregular polythiophene. Macromolecules 2002, 35, 4590-4601. [CrossRef]

7. Leysen, P.; Teyssandier, J.; De Feyter, S.; Koeckelberghs, G. Controlled Synthesis of a Helical Conjugated Polythiophene. Macromolecules 2018, 51, 3504-3514. [CrossRef]

8. Liu, Y.L.; Pauloehrl, T.; Presolski, S.I.; Albertazzi, L.; Palmans, A.R.A.; Meijer, E.W. Modular Synthetic Platform for the Construction of Functional Single-Chain Polymeric Nanoparticles: From Aqueous Catalysis to Photosensitization. J. Am. Chem. Soc. 2015, 137, 13096-13105. [CrossRef] [PubMed]

9. Elsabahy, M.; Heo, G.S.; Lim, S.M.; Sun, G.R.; Wooley, K.L. Polymeric Nanostructures for Imaging and Therapy. Chem. Rev. 2015, 115, 10967-11011. [CrossRef] [PubMed]

10. O'Reilly, R.K.; Joralemon, M.J.; Wooley, K.L.; Hawker, C.J. Functionalization of micelles and shell cross-linked nanoparticles using click chemistry. Chem. Mater. 2005, 17, 5976-5988. [CrossRef]

11. Mavila, S.; Eivgi, O.; Berkovich, I.; Lemcoff, N.G. Intramolecular Cross-Linking Methodologies for the Synthesis of Polymer Nanoparticles. Chem. Rev. 2016, 116, 878-961. [CrossRef] [PubMed]

12. Gois, J.R.; Popov, A.V.; Guliashvili, T.; Serra, A.C.; Coelho, J.F.J. Synthesis of functionalized poly(vinyl acetate) mediated by alkyne-terminated RAFT agents. RSC Adv. 2015, 5, 91225-91234. [CrossRef]

13. Vandeleene, S.; Jivanescu, M.; Stesmans, A.; Cuppens, J.; Van Bael, M.J.; Verbiest, T.; Koeckelberghs, G. Influence of the Supramolecular Organization on the Magnetic Properties of Poly(3-alkylthiophene)s in Their Neutral State. Macromolecules 2011, 44, 4911-4919. [CrossRef]

14. Hammer, B.A.G.; Bokel, F.A.; Hayward, R.C.; Emrick, T. Cross-Linked Conjugated Polymer Fibrils: Robust Nanowires from Functional Polythiophene Diblock Copolymers. Chem. Mater. 2011, 23, 4250-4256. [CrossRef]

15. Iovu, M.C.; Jeffries-El, M.; Sheina, E.E.; Cooper, J.R.; McCullough, R.D. Regioregular poly(3-alkylthiophene) conducting block copolymers. Polymer 2005, 46, 8582-8586. [CrossRef] 
16. Verheyen, L.; Leysen, P.; Van den Eede, M.P.; Ceunen, W.; Hardeman, T.; Koeckelberghs, G. Advances in the controlled polymerization of conjugated polymers. Polymer 2017, 108, 521-546. [CrossRef]

17. Van Camp, W.; Germonpre, V.; Mespouille, L.; Dubois, P.; Goethals, E.J.; Du Prez, F.E. New poly(acrylic acid) containing segmented copolymer structures by combination of "Click" chemistry and atom transfer radical polymerization. React. Funct. Polym. 2007, 67, 1168-1180. [CrossRef]

18. Craley, C.R.; Zhang, R.; Kowalewski, T.; McCullough, R.D.; Stefan, M.C. Regioregular Poly(3-hexylthiophene) in a Novel Conducting Amphiphilic Block Copolymer. Macromol. Rapid Commun. 2009, 30, 11-16. [CrossRef] [PubMed]

19. Jeffries-El, M.; Sauve, G.; McCullough, R.D. Facile synthesis of end-functionalized regioregular poly(3-alkylthiophene)s via modified Grignard metathesis reaction. Macromolecules 2005, 38, 10346-10352. [CrossRef]

20. Miyakoshi, R.; Yokoyama, A.; Yokozawa, T. Catalyst-transfer polycondensation. Mechanism of Ni-catalyzed chain-growth polymerization leading to well-defined poly(3-hexylthiophene). J. Am. Chem. Soc. 2005, 127, 17542-17547. [CrossRef] [PubMed]

21. Kamigaito, M.; Ando, T.; Sawamoto, M. Metal-Catalyzed Living Radical Polymerization. Chem. Rev. 2001, 101, 3689-3746. [CrossRef] [PubMed]

22. Matyjaszewski, K.; Xia, J. Atom Transfer Radical Polymerization. Chem. Rev. 2001, 101, 2921-2990. [CrossRef] [PubMed]

23. Huisgen, R. Cycloadditions-Definition, Classification, and Characterization. Angew.Chem. Int. Ed. Engl. 1968, 7, 321-328. [CrossRef]

24. Kolb Hartmuth, C.; Finn, M.G.; Sharpless, K.B. Click Chemistry: Diverse Chemical Function from a Few Good Reactions. Angew. Chem. Int. Ed. 2001, 40, 2004-2021. [CrossRef]

25. Binder Wolfgang, H.; Sachsenhofer, R. 'Click' Chemistry in Polymer and Materials Science. Macromol. Rapid Commun. 2007, 28, 15-54. [CrossRef]

26. Satyanarayama, T.; Abraham, S.; Kagan, H.B. Nonlinear Effects in Asymmetric Catalysis. Angew. Chem. Int. Ed. 2009, 48, 456-494. [CrossRef] [PubMed]

27. Langeveld-Voss, B.M.W.; Waterval, R.J.M.; Janssen, R.A.J.; Meijer, E.W. Principles of "majority rules" and "sergeants and soldiers" applied to the aggregation of optically active polythiophenes: Evidence for a multichain phenomenon. Macromolecules 1999, 32, 227-230. [CrossRef]

28. Mahadevi, A.S.; Sastry, G.N. Cooperativity in Noncovalent Interactions. Chem. Rev. 2016, 116, $2775-2825$. [CrossRef] [PubMed]

29. Cheng, C.; Qi, K.; Khoshdel, E.; Wooley, K.L. Tandem synthesis of core-shell brush copolymers and their transformation to peripherally cross-linked and hollowed nanostructures. J. Am. Chem. Soc. 2006, 128, 6808-6809. [CrossRef] [PubMed]

30. Huang, H.Y.; Kowalewski, T.; Remsen, E.E.; Gertzmann, R.; Wooley, K.L. Hydrogel-coated glassy nanospheres: A novel method for the synthesis of shell cross-linked knedels. J. Am. Chem. Soc. 1997, 119, 11653-11659. [CrossRef]

(C) 2018 by the authors. Licensee MDPI, Basel, Switzerland. This article is an open access article distributed under the terms and conditions of the Creative Commons Attribution (CC BY) license (http://creativecommons.org/licenses/by/4.0/). 